\title{
Mathematical modeling in task of optimal managing by savings in the middle class
}

\author{
P.O. Derevyankina ${ }^{1, *}$ \\ ${ }^{1}$ Perm National Research Polytechnic University, 29, Komsomolsky prospekt, Perm, Perm krai, Perm, \\ 614990, Russia
}

\begin{abstract}
Consumption and saving balance issues in the middle class, as the most economically active cluster of society, are the subject of extensive expert discussion and require systematic government regulation. The present paper deals with mathematical model of middle class differentiation by savings which dynamics is described by initial boundary value problem with a parabolic equation. This study aims to investigate a case of savings regulation by changing of non-savers share. The paper presents formulation this problem as an optimal boundary control problem for distributed system of savings. Based on the Lagrange principle, the necessary conditions for the solvability of the problem are derived in the form of an optimization system. The optimal control law establishing the relationship between the non-savers share and the structure of the middle class in terms of savings is obtained. The paper also considers an approach to the numerical implementation of the optimal control model in the Comsol Multiphysics simulation software. An example of model calculating for a region of Russia based on real data is given.
\end{abstract}

\section{Introduction}

According to a studies (for example, [1]) in Russia, the financial behavior of the population does not correspond to the classical theoretical model of rational consumption leveling with the help of financial instruments; it is passive, partly patterned, and does not imply long-term financial planning. This inconsistency between the theory and practice of consumption and savings balancing is caused by many problems concerning both the financial environment and its institutions (which cannot guarantee full protection of the interests and rights of households ) and the population itself (whose knowledge and skills in financial matters are low). Solving of these problems requires a systematic state regulation, since a financial inclusion of the population is known to be contributing to a sustainable development of the national economies [2].

The most changeable stratum of society is its middle class, which has a consistently high income, and is also characterized by a high level of education, responsible behavior, rationalization of all areas of its life through continuous development in their professional and daily activities. Therefore, the middle class can be the first to change the model of

\footnotetext{
*Corresponding author: p.derevyankina@bk.ru
} 
financial behavior from passive to active and set an example for the lower strata of society [3].

Many researchers (in particular, $[4,5]$ ) studied the saving behavior of the population and factors influencing it as well as methods of savings stimulating from the point of view of analysis and used micro- and macro data. However, from the point of view of forecasting and control these processes an approach based on mathematical modeling is more powerful. A number of scientists were engaged in the construction and research of a dynamic model of the distribution of savings in society [6,7]. But the optimal management issues went beyond the scope of previous researches. The purpose of this paper is to propose a mathematical model that formalizes the tasks of state regulation of households savings, as well as to develop mathematical and software support for its solution applying the methods of the optimal control theory for a distributed systems to a mathematical model of the savings dynamics.

\section{Statement of the managing problem of households savings in the middle class}

The structure of the Russian society by savings has been suboptimal over the past several decades. Savings of the middle class have a low specific weight in it, and the share of nonsavers is high (about $80 \%$ ). A moderate rejection of the consumer financial behavior model in favor of an investment and savings strategy is beneficial for the middle class households, since such a rationalization of its financial budget will allow it to achieve their financial goals and receive additional investment income, as well as for the entire economic system.

Savings behavior of the middle class is characterized by its differentiation by savings. It's dynamics can be described by a distributed system [6], consisting of a parabolic equation, initial and boundary conditions:

$$
\left\{\begin{array}{l}
\frac{\partial u}{\partial t}+\frac{\partial}{\partial x}(F \cdot u(x, t))-\frac{1}{2} \frac{\partial^{2}}{\partial x^{2}}(b \cdot u(x, t))=0 \\
\left.u\right|_{t=0}=u_{\text {start }} \\
\left.u\right|_{x=0}=u_{0} \\
\left.u\right|_{x=L}=u_{L} .
\end{array}\right.
$$

where $x(x \in[0, L])$ are savings, $t(t \in[0, \tau])$ is time, required function $u(x, t)$ is a share of households in the neighborhood of point $(x, t), b$ is the uncertainty parameter of the system, $\left.u\right|_{t=0}=u_{\text {start }}$ is the given distribution at the initial moment of time, $u_{0}$ is the share of non-savers (i.e., households with savings in the vicinity $x=0), u_{L}-$ share of households with savings in the neighborhood $x=L, F(x, t)$ is the function of the rate of the household budget change, settled according to [7] by the formula

$$
F(x, t)=(1-0,35 \cdot \Theta(\tilde{P}, 1)) \cdot \tilde{P}-\frac{x}{x+1}-0,1 \cdot x \cdot \Theta\left(x, x_{1}\right)
$$

where $\Theta(x, y)=x^{8} \cdot\left(x^{8}+y^{8}\right)^{-1}, \quad \tilde{P}(x)=z-0,015 \cdot x \cdot \Theta\left(x, x_{2}\right), \quad z=z(t) \quad$ is function of the average income, $x_{1}=x_{1}(t), x_{2}=x_{2}(t)$ are functions of the minimum and average prices of elite goods (the demand for which does not fall while income rises).

At the initial moment time all households from the considered cluster are distributed by savings within the interval, i.e. the following equality holds:

$$
\int_{0}^{L} u(x, 0) d x=1 .
$$


Let's consider the task to achieve a given target differentiation of the population by savings $\left(u^{*}(x, \tau)\right)$ to a certain moment of time $\tau$ by controlling the share of non-savers. Introduce the control function

$$
u p r(t)=u(0, t)
$$

and functional of a special kind

$$
J(u, u p r)=\int_{0}^{L}\left(u(x, \tau)-u^{*}(x, \tau)\right)^{2} d t+\alpha \int_{0}^{\tau}|u p r(t)|^{2} d t,
$$

which is continuous, convex and coercive.

In formula (5) $\alpha$ is a certain positive regularization parameter. It can be used to vary the contribution of the second term to the value of the functional. In practice, it is usually try to have a second term commensurate with the measurement error of the function $u$.

The problem of achieving the target distribution $u^{*}(x, \tau)$ by policy measures of saving behavior activating in the middle class can be formulated as a problem of minimizing functional (5) for system (1) and control function (4). This problem belongs to the boundary control and final observation type of optimal control problems by distributed systems. It has a unique solution (optimal control $u p r_{o}$ ) due to the properties of the functional and consists in finding the optimal law of the non-savers share changing over time, which provides the maximum approximation of the households distribution by the amount of savings to the target one.

\section{Optimality system for managing by households savings}

According to the Lagrange principle, the necessary condition for the extremum of functional (5) is that its first variation should be equal to zero:

$$
\delta J\left(u, u p r_{o}\right)=0
$$

The control function enters linearly in the equation of state, as well as in the initial and boundary conditions of the boundary value problem (1). Therefore a linear operator $\Lambda$ can be defined as $\Lambda u p r=u$. Obviously, it can be argued that the equalities are true:

$$
\begin{aligned}
& \lim _{t \rightarrow 0} \frac{\Lambda\left(u p r_{o}+t \delta u p r\right)-\Lambda u p r_{o}}{t}=\lim _{t \rightarrow 0} \frac{\Lambda u p r_{o}+t \Lambda \delta u p r-\Lambda u p r_{o}}{t}=\Lambda \delta u p r, \\
& \lim _{t \rightarrow 0} \frac{\left(u p r_{o}+t \delta u p r\right)-u p r_{o}}{t}=\lim _{t \rightarrow 0} \frac{u p r_{o}+t \delta u p r-u p r_{o}}{t}=\delta u p r
\end{aligned}
$$

where $\delta u p r$ is a variation of optimal control $u p r_{o}, \Lambda \delta u p r$ is a solution variation, which is the derivative of the system state function, taken with respect to the optimal control function at the optimal element.

For the considered control problem (1), (4), (5), the Gateaux derivative of functional (5) on the optimal element $u p r_{o}$ can be written in the form

$$
\left\langle J^{\prime}\left(u p r_{o}\right), \delta u p r\right\rangle=2 \int_{0}^{L}\left(\Lambda u p r-u^{*}\right) \cdot \Lambda \delta u p r d x+2 \alpha \int_{0}^{\tau} u p r_{o} \cdot \delta u p r d t
$$

taking into account equalities (7), (8). From expression (9) follows that in our case condition (6) is equivalent to requirement

$$
\int_{0}^{L}\left(u(x, \tau)-u^{*}(x, \tau)\right) \cdot \dot{\tilde{u}}(x, \tau) d x+\alpha \int_{0}^{\tau} u p r_{o} \cdot \delta u p r d t=0
$$


where $\dot{\tilde{u}}=\Lambda \delta u p r=\Lambda^{\prime} u p r_{o}$ is a solution variation.

Now we obtain conditions that will guarantee the fulfillment of equality (10) according to the Fursikov inference scheme [8] of the necessary conditions for the solvability of the control problem.

As a result of the variation of system (1), we get:

$$
\left\{\begin{array}{l}
\frac{\partial \dot{\tilde{u}}}{\partial t}+\frac{\partial}{\partial x}(F \cdot \dot{\tilde{u}})-\frac{1}{2} \frac{\partial^{2}}{\partial x^{2}}(b \cdot \dot{\tilde{u}})=0, \\
\dot{\tilde{u}}(x, 0)=0, \\
\dot{\tilde{u}}(0, t)=\delta u p r, \\
\dot{\tilde{u}}(L, t)=0 .
\end{array}\right.
$$

Let us write the equation of state for the varied problem (11) after multiplying by an auxiliary function $p(x, t)$ and integrating over the region $[0, L] \times[0, \tau]$ :

$$
\int_{0}^{\tau} \int_{0}^{L} p \frac{\partial \dot{\tilde{u}}}{\partial t} d x d t+\int_{0}^{\tau} \int_{0}^{L} p \frac{\partial}{\partial x}(F \cdot \dot{\tilde{u}}) d x d t-\frac{1}{2} \int_{0}^{\tau} \int_{0}^{L} p \frac{\partial^{2}}{\partial x^{2}}(b \cdot \dot{\tilde{u}}) d x d t=0 .
$$

Let us continue to transform the last expression (11), applying the Green's formula to it and taking into account the initial-boundary conditions of systems (1) and (11):

$$
\begin{gathered}
\left.\int_{0}^{L} p \dot{\tilde{u}}\right|_{t=\tau} d x-\int_{0}^{L} \int_{0}^{\tau} \dot{\tilde{u}} \cdot\left(\frac{\partial p}{\partial t}+F \frac{\partial p}{\partial x}+\frac{1}{2} b \frac{\partial^{2} p}{\partial x^{2}}\right) d x d t-\left.\frac{1}{2} \int_{0}^{\tau} b p \frac{\partial \dot{\tilde{u}}}{\partial x}\right|_{0} ^{L} d t- \\
-\left.\int_{0}^{\tau}\left(p F+\frac{1}{2} b \frac{\partial p}{\partial x}\right) \delta u p r\right|_{x=0} d t=0 .
\end{gathered}
$$

If the function $p(x, t)$ will satisfy the time inverse boundary value problem

$$
\left\{\begin{array}{l}
\frac{\partial p}{\partial t}+F \frac{\partial p}{\partial x}+\frac{1}{2} b \frac{\partial^{2} p}{\partial x^{2}}=0 \\
p(x, \tau)=u(x, \tau)-u^{*}(x, \tau), \\
p(0, t)=0 \\
p(L, t)=0
\end{array}\right.
$$

then equation (13) will be simplified and take the form:

$$
\int_{0}^{L}\left(u(x, \tau)-u^{*}(x, \tau)\right) \cdot \dot{\tilde{u}}(x, \tau) d x-\left.\int_{0}^{\tau}\left(\frac{b}{2} \frac{\partial p}{\partial x} \cdot \delta u p r\right)\right|_{x=0} d t=0 .
$$

Note that in expressions (15) and (10) the first terms are the same; therefore, combining the second terms under the general integral, we arrive at the condition

$$
\int_{0}^{\tau} \delta u p r \cdot\left[\left.\frac{b}{2} \frac{\partial p}{\partial x} \cdot \delta u p r\right|_{x=0}+\alpha u p r_{o}\right] d t=0 .
$$

Whence, due to the arbitrariness of the control variation $\delta u p r(\neq 0)$, we obtain the formula for finding the optimal control law:

$$
u p r_{o}=-\left.\frac{b}{2 \alpha} \frac{\partial p}{\partial x}\right|_{x=0}
$$

Necessary and sufficient conditions for the solvability of the control problem (1), (4), (5) present a joint solution of differential equations system consisting of a direct in time boundary value problem (1) for a function $u(x, t)$ and a time inverse boundary value problem (15) for an conjugate function $p(x, t)$ : 


$$
\left\{\begin{array}{l}
\frac{\partial u}{\partial t}+\frac{\partial(F(x) \cdot u)}{\partial x}-\frac{b}{2} \frac{\partial^{2} u}{\partial x^{2}}=0, \\
u(x, 0)=u_{\text {start }} \\
u(0, t)=-\left.\frac{b}{2 \alpha} \frac{\partial p}{\partial x}\right|_{x=0}, \\
u(L, t)=u_{L} \\
\frac{\partial p}{\partial t}+F(x) \frac{\partial p}{\partial x}+\frac{b}{2} \frac{\partial^{2} p}{\partial x^{2}}=0, \\
p(x, \tau)=u(x, \tau)-u^{*}(x), \\
p(0, t)=0 \\
p(L, t)=0 .
\end{array}\right.
$$

Thus, the main idea of the proposed approach to managing the differentiation of households by the amount of savings as a task of enhancing the saving behavior of the population from a mathematical point of view is to solve the optimization system (18) and find the optimal law for reducing the share of non-savers over time according to rule (17).

\section{Software implementation of the numerical solution of the problem of managing households savings in the middle class}

In the previous paragraph of the article, it was shown that the solution to the original optimal control problem (1), (4), (5) can be replaced by the solution to the optimization system (18), which does not include the explicit control function, that is an undoubted advantage of the proposed approach.

Applying an interactive environment for modeling and simulation COMSOL Multiphysics, a software tool was developed for solving the direct problem (1) and the control problem to automate the process of determining the numerical values of the optimal control actions on the dynamics of the middle class savings. The functionality of the basic platform was used. The software tooling development process was driven by the logic of the Model Builder. The interface of the group "Mathematics" (Mathematics, PDE Interfaces) made it possible to create and customize the description of our own model.

To solve the direct problem, the distributed system (1) was reduced to the general coefficient form of partial differential equations used in COMSOL, and supplemented with the Initial Value and Dirichlet Boundary Condition.

The main idea of solving the control problem was following. Optimization system (18) was split into two distributed systems (the first system with respect to the sought function $u(x, t)$ is system (1) taking into account (17), the second system with respect to the conjugate function $p(x, t)$ is system (18)), which were solved iteratively. At the first iteration, it was set that $p=0$. Starting from the second iteration, system (18) was solved at even iterations, and the values of the function $u(x, t)$ were taken from the solution of the previous iteration; at odd iterations, system (1) was solved taking into account equality (17), and the values of the function $p(x, t)$ were taken from the solution of the previous iteration.

In the course of the solution, the parameter $\alpha$ was selected manually. The iterative process was stopped when the difference between solutions at subsequent iterations did not exceed a predetermined value.

Thus, the software toolkit implements the numerical solution of the optimization system to obtain quantitative estimates of the impact of the share of households with low savings on the dynamics of the volume and structure of savings in the middle class, as well as to visualize the calculation results, to form data arrays for further analysis. 


\section{An example of solving the problem of optimal control for the region of Russia}

The optimization problem of the savings structure in the middle class of the Perm region is considered. Households with an average per capita average monthly income of 1.5 of the average per capita average monthly income in the region were classified as the middle class. The unit of measurement of savings accepted the living wage. The parameters of model (1) were determined as follows. Based on the official statistics of the Perm Region [9] for the period from 2003 till 2018 years, a time series $z(t)$ of changes in average per capita incomes in the middle class taking into account inflation, was compiled (Fig. 1.a). According to expert estimates given in [7], the initial values of the functions of the minimum $x_{1}(t)$ and average $x_{2}(t)$ prices of elite goods and a constant noise value $b=6$ are set. The dynamics of prices for elite goods over time taking into account inflation is shown in Fig. 1.b.
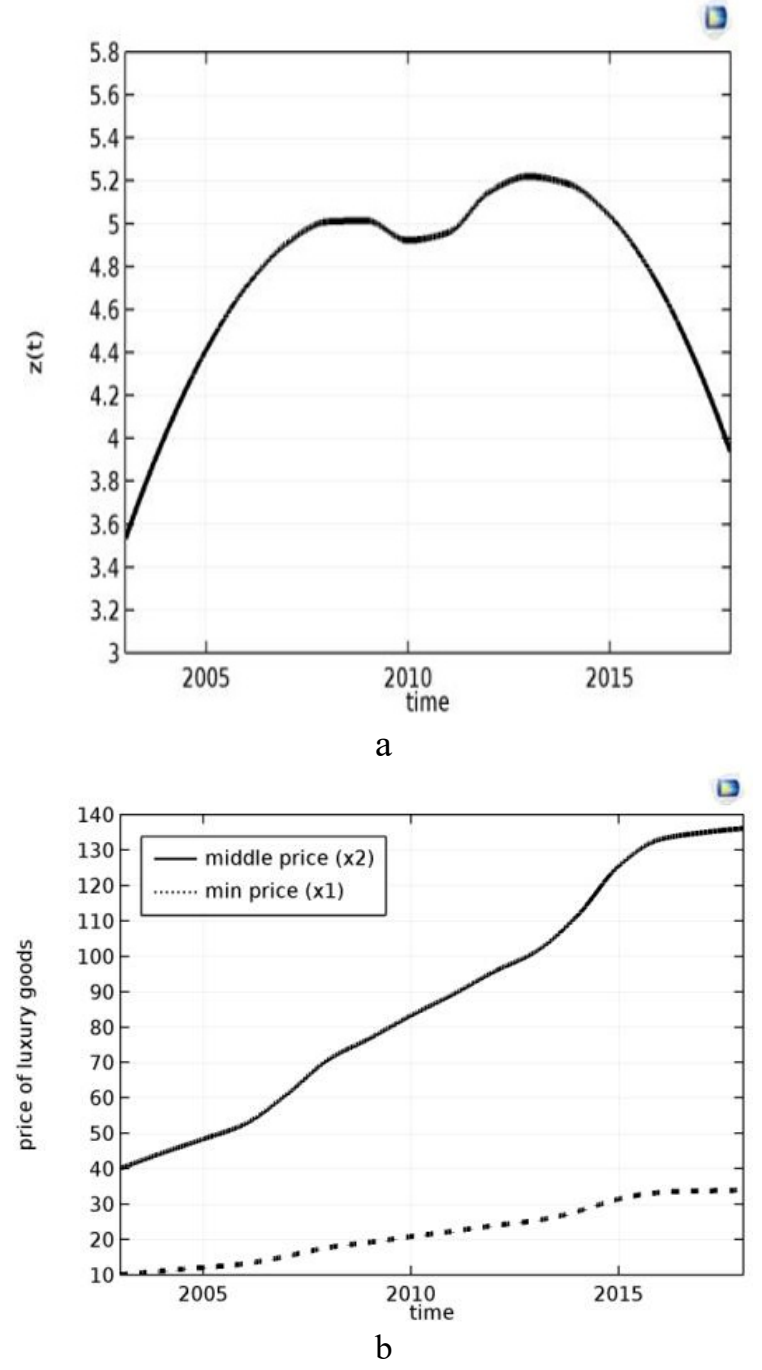

Fig. 1. The dynamics of changes in the values (in living wages): a - average per capita income in the middle class; $b$ - price for elite goods. 
The rate $F(x, t)$ of change of the households savings was calculated using formula (2), its graph is presented in Fig. 2.a for 2003 year and 2019 year. The dynamics of change of non-savers share in the middle class $u_{0}(t)$ was calculated for the period from 2003 year till 2019 year based on materials [10,11], its graph is shown in Fig.2.b. The share of households with the highest savings was assumed to be zero: $u_{L}=0$.

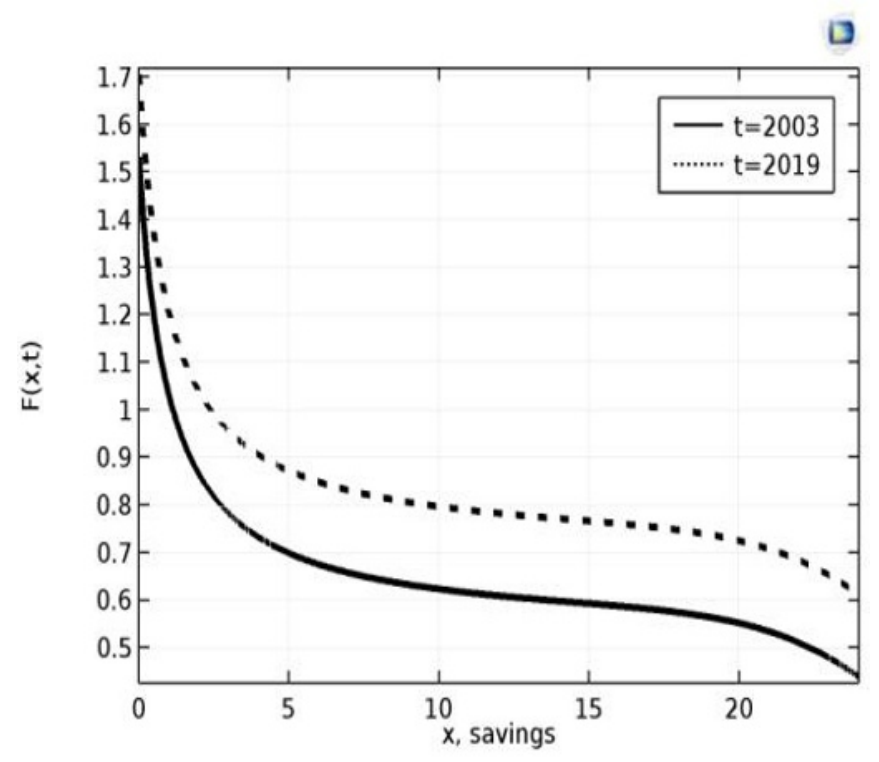

a

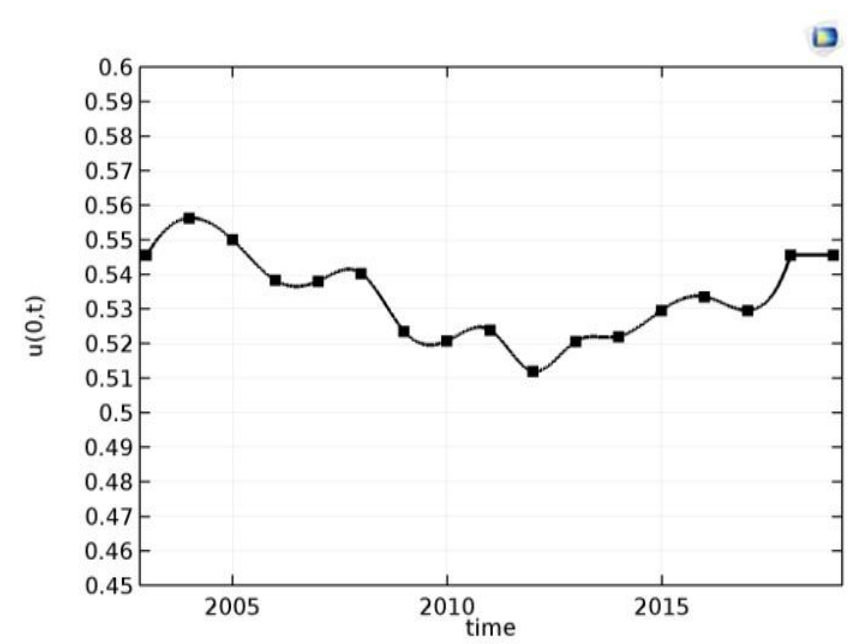

b

Fig. 2. Dynamics of changes in values in the middle class (in the living wages): a - the rate of change in savings in 2003 year and 2019 year; b - share of non-savers.

The direct problem was solved with the specified parameters: the distribution of middle class households by savings for the Perm Region in 2019 year was calculated. And it was taken as the initial function in the management problem. The management goal was to achieve by 2023 year a target distribution $u^{*}$ with a $40 \%$ share of non-savers. As a target 
function was taken the parabolic function shown in Fig. 3.a. The solution of the optimality system (18) was performed using the developed software toolkit in Comsol Multiphysics. The optimal law for reducing the proportion of non-savers, calculated by formula (17), is shown in Fig. $3 b$.

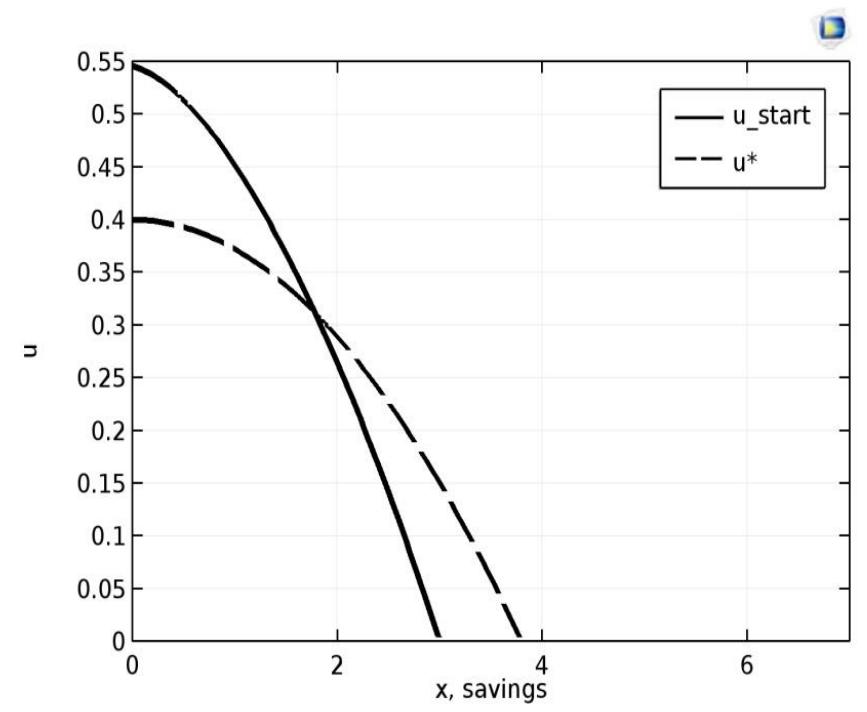

a

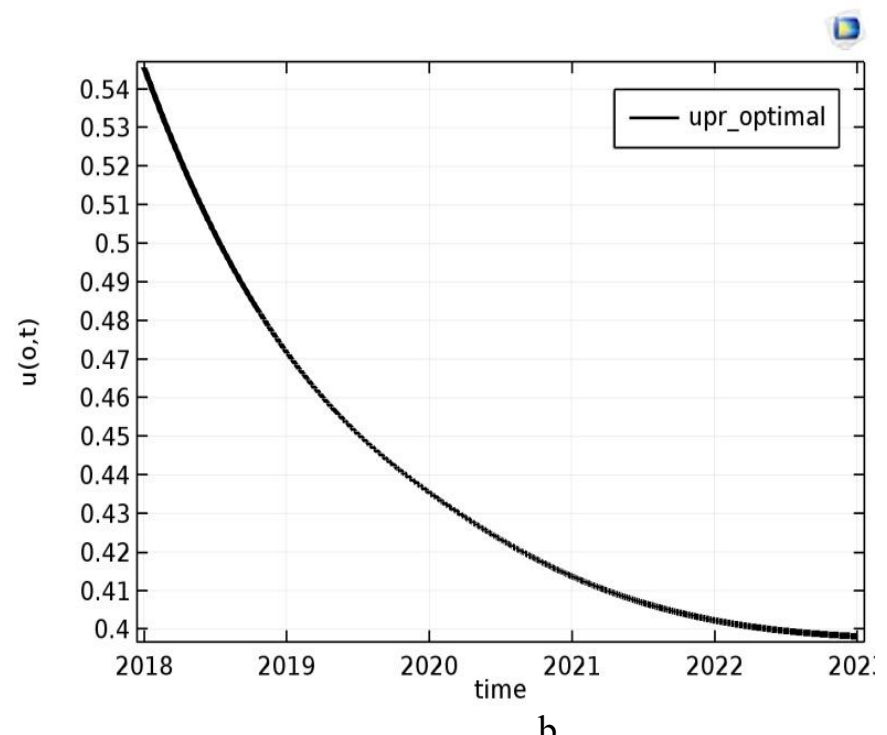

Fig. 3. a - Initial (solid) and target (dotted line) savings distribution in the middle class of the Perm Territory; $b$ is the optimal law for the reduction of the share of non-savers in the middle class of the Perm Region over time.

Thus, an example of calculating the control model based on real data is given.

\section{Conclusion}


This article proposes a mathematical model of the problem of regulating the savings of the middle class using the methods of the optimal control theory to differentiate of households by the amount of savings. The case of regulation of the share of non-savers corresponding to the boundary control is considered. Using the Lagrange principle, an optimality system was constructed, which is a necessary and sufficient condition for the solvability of the formulated control problem, and a formula was obtained to determine the optimal change in the share of non-savers. An approach to solving the optimality system, taking into account its peculiarities in the interactive modeling environment Comsol Multiphysics, is described, which consists in the iterative solution of a time direct boundary value problem for the desired function and an time inverseboundary value problem for an auxiliary function. An example of the numerical implementation of the model on real data for the region of Russia is given. The law of reduction of the share of non-savers over time is calculated. The obtained quantitative estimates of the change the share of non-savers, which optimize the structure of savings in the cluster, can be considered as planned targets for measures within the policy of stimulating the saving behavior in middle class households in the region.

\section{References}

1. Grigoriev L, Salmina A and Kuzina O 2009 Russian middle class: analysis of structure and financial behavior (Moscow: Ekon-inform) p 148

2. Gould D and Melecky M 2017 Risks and Returns: Managing Financial Trade-Offs for Inclusive Growth in Europe and Central Asia (Washington, DC: World Bank) doi:10.1596/978-1-4648-0967-5

3. Avraamova E M and Maleva T M 2014 Social Sciences and modernity 45

4. Hüfner F and Koske I 2010 Explaining Household Saving Rates in G7 Countries: Implications for Germany (Paris: OECD Publishing OECD Economics Department, Working Papers) 75425 https://doi.org/10.1787/5kmjv81n9phc-en

5. De Mello L, Kongsrud P and Price R 2004 Saving Behavior and the Effectiveness of Fiscal Policy (Paris: OECD Publishing OECD Economics Department, Working Papers) 397 Retrieved from: https://www.oecd.org/economy/publicfinance/34081006.pdf

6. Erofeenko V T and Kozlovskaya I S 2004 Partial differential equations and mathematical models in Economics: lectures (Moscow: editorial URSS) p 248

7. Chernavskii D S and Pirogov G G 1996 News Univ., Appl. Nonlinear Dyn. 4(3) 67

8. Fursikov A V 1999 Optimal control of distributed systems. Theory and applications (Novosibirsk: Scientific book) p 352

9. Official Statistics of Perm Region https://permstat.gks.ru/ofstatistics

10. The Russia Longitudinal Monitoring Survey http://www.cpc.unc.edu/projects/rlms

11. The middle class in modern Russia: 10 years later 2014 (Moscow: Institute of sociology of the Russian Academy of Sciences) p 222 